Original Contribution

\title{
COMPARATIVE ANALYSIS OF THE POSTVACCINAL IMMUNE RESPONSE IN SHEEP IN TWO FARMS AFTER VACCINATION AGAINST INFECTIOUS AGALACTIA - A FIELD STUDY
}

\author{
C. Evstatiev, K. Gospodinova, V. Petrov* \\ ${ }^{1}$ Department of Veterinary Microbiology, Infectious and Parasitic Diseases, Faculty of \\ Veterinary Medicine, Trakia University, Stara Zagora, Bulgaria
}

\begin{abstract}
The aim of the present study was to detect differences in immune response in sheep from 2 small extensive farms against contagious agalactia, after treatments against helminths and optimization of the diet (farm 2). The one-year experimental period was divided into 2 six-months subperiods. The first without intervention, the second after changes in some of the management conditions. Samples for every subperiods, obtained from the day of vaccination and 3, 7, 14, 30, 60, 90, 120, 180 days thereafter were examined. The samples were assayed by means of indirect ELISA. It was found that the antibody titer increased rapidly after administration of the vaccine, reached a maximum between 7 and 30 days, and decreased rapidly after the 90th day of the experimental period. Significantly higher $(\mathrm{P}<0.05)$ antibody titers were found in farm 2 after anti-parasite treatments compared to farm 1.
\end{abstract}

Key words: Mycoplasma agalactia, Contagious agalactia, Sheep, Vaccines, ELISA

\section{INTRODUCTION}

Contagious agalactia is an infectious disease in sheep and goats caused by several Mycoplasma species with the leading role of Mycoplasma agalactiae $(M$. agalactiae) $(1,2)$. This is among the most serious and economically relevant diseases affecting dairy small ruminants. Caused losses are due to lower milk production and the shorter production life of infected animals. Contagious agalactia is in the World Organisation for Animal Health (OIE) list of notifiable diseases. At present, the disease is encountered in most countries with intensive sheep and goat farming in the Mediterranean region and the Balkan peninsula, where the disease is endemic (3-5). Clinical signs are numerous, including mastitis, arthritis, keratoconjunctivitis, pneumonia and septicaemia, manifested in various combinations (6). The spread of the infection in the affected farms is rapid and

\footnotetext{
*Correspondence to: Vladimir Petrov,

Department of Veterinary Microbiology, Infectious and Parasitic Diseases, Faculty of Veterinary Medicine, Trakia University, 6000 Stara Zagora, Bulgaria,e-mail:vlado72@abv.bg +35942 699610
}

after a short period of time can affect up to 30$85 \%$ of the animals (7). The control of the disease is performed by chemotherapy, vaccination and good farm management practices. Long-term treatment is required, yet eradication is sometimes unsuccessful, with frequent clinical recurrence. The treatment with antibiotics reduces the severity of main symptoms but does not eliminate carriership, so that a clinically recovered animal could still a source of infection (8). In Europe, vaccination was approved since the 1970s (9) but only after the 1990s, it is extensively practiced. Now, live vaccines against $M$. agalactiae are not acceptable in Europe, so the attention is focused on using formalin-killed products with oil-emulsion adjuvants e.g. aluminium hydroxide. Inactivated monovaccines against $M$. agalactiae or combined with $M$. capricolum subsp. capricolum and M. mycoides subsp. capri. are predominantly used. The real efficiency of these vaccines is still questionable, especially in the field $(2,6)$.

The present study aimed to evaluate and compare the immune response in sheep reared 
under various production systems after application of a commercial vaccine against contagious agalactia.

\section{MATERIAL AND METHODS STUDY DESIGN}

The 1-year experimental period was divided into two 6-month subperiods in line with the vaccination scheme against contagious agalactia adopted in farms. The first period was from November 2018 to April 2019, and the second - from May to October 2019. Eight animals from each farm were followed out.

Blood samples were collected from the jugular vein of all experimental animals on the day of vaccination (day 0) and post vaccination days $3,7,14,30,60,90,120,180$. The day 0 of the second 6-month period coincided with the $180^{\text {th }}$ day of the first subperiod. Blood was collected in plain vacutainers. Sera were separately collected by centrifugation and kept at $-20^{\circ} \mathrm{C}$ until use.

\section{EXPERIMENTAL ANIMALS}

The field study was conducted in two farms. The study period was 1 year. Neither antibiotic therapy nor another specific treatment against Mycoplasma was performed during the time of the experiment.

\section{FARM 1}

The farm comprised 55 mixed-breed sheep. They were housed in a barn with indoor and outdoor parts. Sheep were fed alfalfa hay, straw, ground grain (corn, barley and wheat) and grazed on pasture. According to the owner, he performed in person the prophylactic treatment against helminths twice per year. At 6-month intervals (upon owner's decision), sheep were vaccinated against contagious agalactia. Eight sheep at 2-5 years of age with previous vaccinations were randomly chosen.

\section{FARM 2}

The farm had 24 mixed-breed sheep. They were reared in a part of the house's backyard, adapted for the barn with indoor and outdoor parts. Animals grazed on pasture and were supplemented with concentrate, alfalfa or hay. Often, they were mixed with other farms on the pasture. A separate premise was used for lambing. Growing lambs were reared separately. Prophylactic treatments against helminths were done in the spring and the autumn. At 6-month intervals (upon owner's decision), sheep were vaccinated against contagious agalactia. Eight sheep at 2-5 years of age with previous vaccinations were randomly chosen.

In this farm, after the first 6-month period, dehelminthization with oxyclozanide (Douvistome, CEVA Santé Animale) at a dose of $22.5 \mathrm{mg} / \mathrm{kg} \mathrm{BW}$ and albendazole (Vermitan 10\%, CEVA Santé Animale) at a dose of 7.5 $\mathrm{mg} / \mathrm{kg}$ bw was done. The usual ration of animals was supplemented with concentrate for small ruminants.

\section{VACCINE}

A commercial phenol-inactivated combined vaccine Agalax-S with aluminium hydroxide as an adjuvant (Laboratorio SYVA) was used; the vaccine was stored as required by the manufacturer and applied at a dose recommended by the manufacturer.

\section{ELISA}

Samples were assayed with commercial indirect ELISA kit - ID Screen Indirect Mycoplasma agalactiae (IDvet, 310, rue Louis Pasteur - Grabels - France). The kit was designed for the detection of antibodies against Mycoplasma agalactiae, causing contagious agalactia in small ruminants (sheep, goats).

The wells of plates were coated with purified M. agalactiae $\mathrm{P} 48$ recombinant protein, used as the target antigen. If samples contained antiP48 antibodies, an antigen-antibody complex were formed, fixed to the bottom of wells by adding a conjugate - horseradish peroxidase (HRP). After washing of wells to remove excess conjugate, substrate solution was added to visualize the reaction (blue coloration). In the presence of antibodies, the blue colour turned yellow after adding the stop solution.

The microplate was read at $450 \mathrm{~nm}$ by means of ELISA reader LEDETEC LABEXIM PRODUCT.

For each sample, the S/P percentage was calculated by the formula:

$$
\mathrm{S} / \mathrm{P} \%=\frac{\text { OD sample }- \text { OD negative control (NC) }}{\text { OD positive control ( } \mathrm{PC})-\mathrm{OD} \mathrm{NC}} \times 100
$$

Samples with $\mathrm{S} / \mathrm{P} \% \leq 50 \%$ were considered negative, samples with $50 \%<\mathrm{S} / \mathrm{P} \% \leq 60 \%$ were interpreted as doubtful and those with $\mathrm{S} / \mathrm{P} \% \geq$ $60 \%$ - as positive. 


\section{STATISTICAL ANALYSIS}

Data were analyzed with GraphPad Prism 7.04 (GraphPad Software Inc., La Jolla, CA) by one-way ANOVA to determine Mean (x), standard error of mean (SEM) values, and the statistically significant differences between mean values of all data. $\mathrm{P}<0.05$ was considered statistically significant.

\section{RESULTS \\ FARM 1}

The results from the serological tests (Table 1) demonstrated a gradual increase in antibody titer during the first two post vaccination weeks, followed by decrease. Maximum S/P\% $(141.1 \pm 13.49)$ was detected by the $14^{\text {th }}$ day. Values close to baseline $(96.15 \pm 18.01)$ were attained by post vaccination day $90(98.17 \pm$ 9.794). On the $180^{\text {th }}$ day of the study, S/P\% values $(88.54 \pm 27.75)$ were lower than the initial ones, yet close to them. Similar trends were observed during the second 180-day period. Maximum S/P\% values (129.4 \pm 25.07), slightly lower than those of the first subperiod, were attained again at post vaccination day 14 . Values close to baseline were found out on day 120. There were no statistically significant differences between results.

\section{FARM 2}

In this farm, during the first 6-month period, $\mathrm{S} / \mathrm{P} \%$ increase was slower and maximum values $(181.8 \pm 32.89)$ were attained on post vaccination day 30 . The decline to initial levels $(99.18 \pm 25.16)$ occurred on day $120(99.43 \pm$ 24.12). The results during the next 6-month period were slightly different. Initial levels $(79.13 \pm 30.97)$ were lower than those from the first subperiod. The $\mathrm{S} / \mathrm{P} \%$ value by post vaccination day $14-167.2 \pm 34.21$, was statistically significantly higher $(\mathrm{P}<0.05)$ compared to the value on the $7^{\text {th }}$ day. Until the end of the monitoring period, $\mathrm{S} / \mathrm{P} \%$ values remained higher than baseline ones.

In both studied farms, $\mathrm{S} / \mathrm{P} \%$ throughout all sampling intervals were higher than $60 \%$ and were interpreted as positive.

The summarized results from the two farms from both experimental periods are presented in Table 1.

Table 1. Kinetics of serological responses (ELISA test) in sheep from farm 1 and farm 2, immunized with commercial vaccine against contagious agalactia.

\begin{tabular}{|c|c|c|c|c|}
\hline & \multicolumn{4}{|c|}{$\mathrm{S} / \mathrm{P} \%$} \\
\hline & \multicolumn{2}{|c|}{ Farm 1} & \multicolumn{2}{|c|}{ Farm 2} \\
\hline & First period & Second period & First period & Second period \\
\hline Day 0 Mean \pm SEM & $96.15 \pm 18.01$ & $88.54 \pm 27.75$ & $99.18 \pm 25.16$ & $79.13 \pm 30.97$ \\
\hline Day 3 Mean \pm SEM & $98.26 \pm 20.89$ & $80.13 \pm 28.88$ & $98.25 \pm 28.38$ & $70.69 \pm 28.77$ \\
\hline Day 7 Mean \pm SEM & $130.7 \pm 10.28$ & $125.2 \pm 34.76$ & $104.6 \pm 28.13$ & $167.2 \pm 34.21^{* a}$ \\
\hline Day 14 Mean \pm SEM & $141.1 \pm 13.49$ & $129.4 \pm 25.07$ & $114.2 \pm 22.04$ & $174.9 \pm 22.17^{\mathrm{a}}$ \\
\hline Day 30 Mean \pm SEM & $126.2 \pm 10.8$ & $112.7 \pm 23.92$ & $181.8 \pm 32.89$ & $175.8 \pm 19.52^{\mathrm{a}}$ \\
\hline Day 60 Mean \pm SEM & $111.9 \pm 9.954$ & $111.0 \pm 18.72$ & $153.8 \pm 32.71$ & $163.1 \pm 15.65^{\mathrm{a}}$ \\
\hline Day 90 Mean \pm SEM & $98.17 \pm 9.794$ & $105.1 \pm 20.87$ & $145 \pm 35.96$ & $119.5 \pm 10.89$ \\
\hline Day 120 Mean \pm SEM & $88.4 \pm 8.922$ & $82.31 \pm 19.32$ & $99.43 \pm 24.12$ & $112.7 \pm 6.277$ \\
\hline Day 180 Mean \pm SEM & $88.54 \pm 27.75$ & $68.0 \pm 13.51$ & $79.13 \pm 30.97$ & $108.2 \pm 9.257$ \\
\hline
\end{tabular}

* $\mathrm{P}<0.05$ compared to the preceding period; a $\mathrm{P}<0.05$ between both farms

The comparison of post-vaccination immune response against contagious agalactia in the two farms showed a very similar response during both subperiods with maximum levels by post-vaccination days 7-14 followed by gradual reduction (Figure 1).
During the first 6-month period antibody titers did not differ substantially between farms, yet during the next 6-month period, farm 2 attained statistically significantly higher titers $(\mathrm{P}<0.05)$ between post vaccination days 7-60. After the third post vaccination month, values of farm 2 remained insignificantly higher than those in farm $1(\mathrm{P}>0.05)$. 


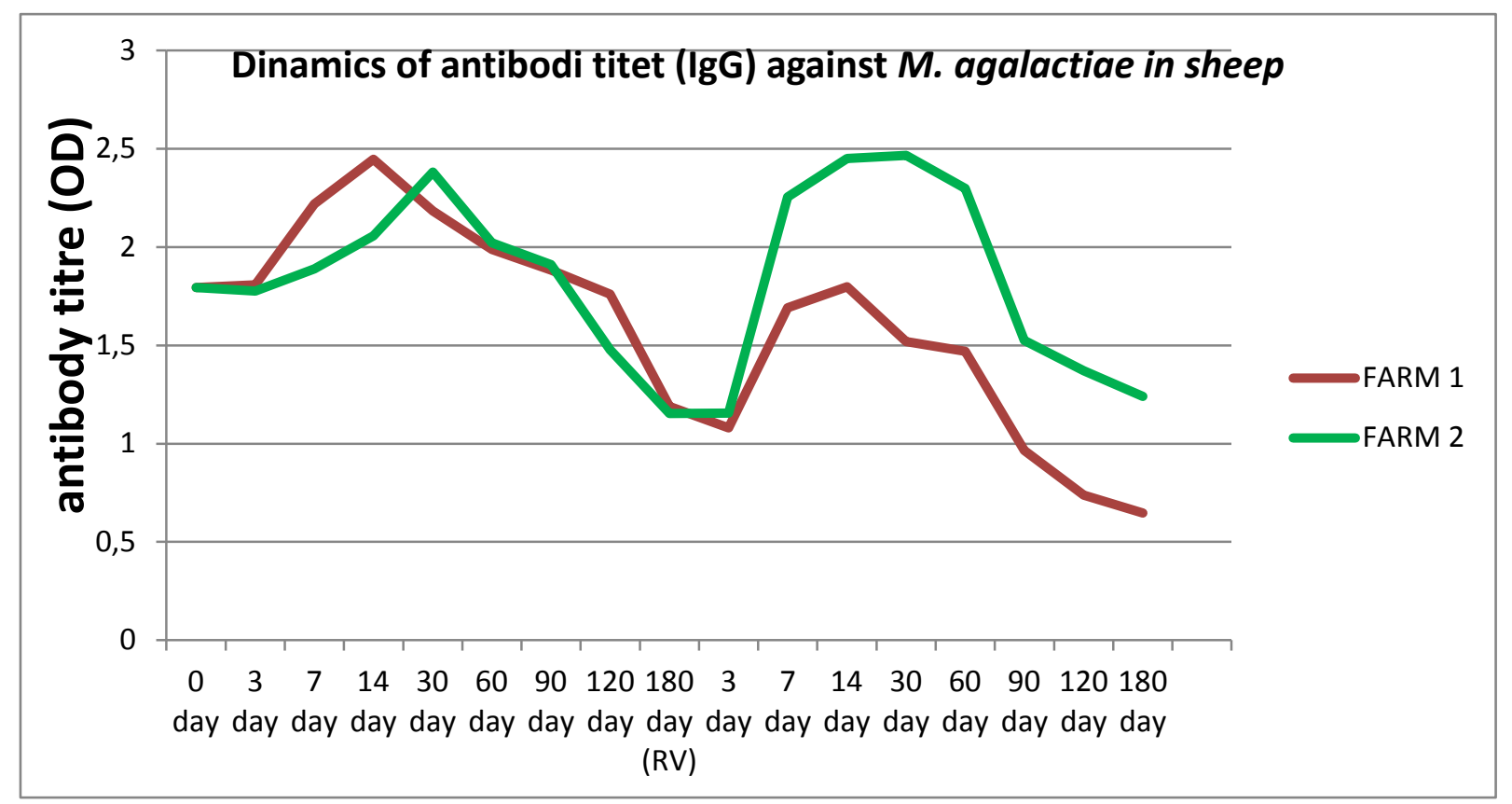

Figure 1. Dynamics in antibody titer (IgG) against $M$. agalactiae in sheep

\section{DISCUSSION}

Vaccination together with hygienic measures is the essence of prevention of clinical contagious agalactia in farms from endemic regions. At the same time, several factors as endo- and ectoparasitic infections, feeding, pregnancy, lactation, stress etc. influence the buildup of active post vaccinal immunity. Most studies on immune response after application of inactivated vaccines were carried out in experimental conditions under optimum conditions for follow-up of immunogenicity and safety of tested products. The literature data from field studies are scarce. The present study compared the effect of some changes in farm management on the buildup of active immunity after vaccination with a commercial vaccine against contagious agalactia.

In this study, antibody titers increased rapidly during the first 2 weeks after the vaccination and declined progressively to baseline values by the third month. Similar results were presented from tests of different experimental vaccines. For example, the test of an inactivated vaccine in Turkey (10) demonstrated the appearance of antibodies 2 weeks after the vaccination, with peak on the $4^{\text {th }}$ experimental week and progressive reduction until post vaccination week 10 .

In another research on the efficacy of saponinand phenol-inactivated vaccines, Tola et al., (11) reported high antibody titers with two peaks: one during the third month, and the second -8 months after the vaccination. They have vaccinated animals before breeding and during pregnancy. The researchers also used ELISA for the detection of antibodies in vaccinated sheep. Reported results are similar to ours - in our study, one peak was also identified by the $1^{\text {st }}$ post vaccination week and a second one during the $7^{\text {th }}$ month, attributed to the revaccination.

A recent study by El-Yazid et al., (12) having tested several experimental vaccines, a peak in antibody response to phenol-inactivated vaccine containing aluminium hydroxide was reported on the $8^{\text {th }}$ week after application. This result differed from ours; the difference was due to the fact that animals were not previously vaccinated while sheep in our experiment had a history of several previous vaccinations.

Several other studies on experimental and commercial vaccines in sheep demonstrated maximum antibody levels between post vaccination days $14-30(7,13-15)$ - results in agreement with ours.

The results from the first period (11.201804.2019) showed a very comparable reactivity pattern of sheep from both farms. Relatively high initial values and the rapid increase in antibody titers showed that the animals were prepared from the upcoming winter. The reduction to levels lower than baseline by days 
120 and 180 could be attributed with their excretion with colostrum and milk of lactating sheep.

The statistically significant differences in sheep response established during the second period in the two farms could be explained with the scheme for antiparasitic treatment and nutrition practiced at farm 2. These assumptions, however, need a more prolonged and more detailed investigations before being confirmed.

The summarized results from the present study outlined the tendency for a decrease in OD values below baseline levels 4 months after application of the vaccine. This means that immunisation schedules form these farms should be reconsidered and vaccinations should be done at 4-month intervals. A similar opinion is shared by Regalla (16), who recommended immunisation three times per year although he considered the efficacy of vaccination inconsistent and non-satisfactory when animals were housed in an environment with very high Mycoplasma contamination. León et al (17) also recommended the application of three doses of vaccine before and one dose after lambing for control of the disease.

\section{REFERENCES}

1. Da Massa, A. J., Wakenell, P. S., \& Brooks, D. L. Mycoplasmas of goats and sheep. Journal of Veterinary Diagnostic Investigation, 4(1): 101-113, 1992.

2. Bergonier, D., Berthelot, X., \& Poumarat, F. Contagious agalactia of small ruminants: current knowledge concerning epidemiology, diagnosis and control. Revue Scientifique et Technique-Office International des Epizooties, 16(3): 848873, 1997.

3. Chazel, M., Tardy, F., Le Grand, D., Calavas, D., \& Poumarat, F. Mycoplasmoses of ruminants in France: recent data from the national surveillance network. BMC Veterinary Research, 6(1): Article number 32, 2010.

4. De la Fe, D., Assuncao, P., Antunes, T., Rosales, R. S., \& Poveda, J. B. Microbiological survey for Mycoplasma spp. in a contagious agalactia endemic area. The Veterinary Journal, 170(2): 257-259, 2005.

5. Corrales, J. C., Esnal, A., De la Fe, C., Sánchez, A., Assunçao, P., Poveda, J. B., \&
Contreras, A. Contagious agalactia in small ruminants. Small Ruminant Research, 68(12): 154-166, 2007.

6. Nicholas, R., Contagious agalactia. The State Veterinary Journal, 5: 13-15, 1995.

7. Campos, A. C., Azevedo, E. O., Alcântara, M. D. B., Silva, R. B. S., Cordeiro, A. A., Mamede, A. G., ... \& Castro, R. S. Efficiency of inactive vaccines against contagious agalactia in Brazil. Arquivo Brasileiro de Medicina Veterinária e Zootecnia, 65(5): 1394-1402, 2013.

8. Azevedo, E. O. D., Alcântara, M. D. B. D., Nascimento, E. R. D., Tabosa, I. M., Barreto, M. L., Almeida, J. F. D., ... \& Castro, R. S. D. Contagious agalactia by Mycoplasma agalactiae in small ruminants in Brazil: first report. Brazilian Journal of Microbiology, 37(4): 576-581, 2006.

9. Foggie, A., Etheridge, J. R., Erdag, O., \& Arisoy, F. Contagious agalactia of sheep and goats preliminary studies on vaccines. Journal of Comparative Pathology, 80(3): 345-358, 1970.

10.Erdag, O. Investigations on the preparation and application of vaccine against contagious Mycoplasma agalactiae or sheep and goats in Turkey. In Proceeding of International Symposium on Mycoplasmosis and Theileriosi (pp. 20-22), 1989.

11.Tola, S., Manunta, D., Rocca, S., Rocchigiani, A. M., Idini, G., Angioi, P. P., \& Leori, G. Experimental vaccination against Mycoplasma agalactiae using different inactivated vaccines. Vaccine, 17(22): 2764-2768, 1999.

12.El-Yazid, H. A., Soliman, R., Wasif, I. M., Selim, S. A. E., Balata, M., Mahmood, Z., $\&$ Seida, A. A. Protective efficacy of the inactivated adjuvant vaccines against Mycoplasma agalactiae infection in goats. International Journal of Veterinary Science, 8(1): 14-19, 2019.

13.Buonavoglia, D., Greco, G., Quaranta, V., Corrente, M., Martella, V., \& Decaro, N. An oil-emulsion vaccine induces fullprotection against Mycoplasma agalactiae infection in sheep. MicrobiologicaQuarterly Journal of Microbiological Sciences, 31(1): 117-124, 2008.

14.Buonavoglia, D., Greco, G., Corrente, M., Greco, M. F., D’Abramo, M., Latronico, F., ... \& Decaro, N. Long-term immunogenicity and protection against Mycoplasma agalactiae induced by an oil 
adjuvant vaccine in sheep. Research in Veterinary Science, 88(1): 16-19, 2010.

15.Botus,, D., Ene, G., Culcescu, M., Popa, V., \& Daneș, M. Evaluation of immune response in sheep after vaccination against contagious agalactia. Lucrari StiintificeUniversitatea de Stiinte Agricole a Banatului Timisoara, Medicina Veterinara, 50(1): 30-38, 2017.

16.Regalla, J. Notes on the contagious agalactia syndrome in Portugal.
Agriculture: Contagious Agalactia and Other Mycoplasmal Diseases of Small Ruminants, European Communities, Luxembourg, 7-10, 1987.

17.León, L. V., Garrido, F. A., Cubero, M. P., \& Perales, A. Immunoprophylaxis of caprine contagious agalactia due to Mycoplasma agalactiae with an inactivated vaccine. The Veterinary Record, 137(11): 266-269, 1995. 